\title{
Design and Simulation of Rectangular Patch Micro Strip Antenna for Linear Polarization Application
}

\author{
Rahul Koshti \\ Mukesh Patel School of Technology Management \\ \& Engineering, Shirpur
}

\author{
Aadesh Mittal \\ Mukesh Patel School of Technology Management \\ \& Engineering, Shirpur
}

\begin{abstract}
A compact Antenna is highly intended to meet the portable communication system requirement. Small size, large gain, better directivity and low power requirement are the key features of such antenna. The polarization of antenna depends on the application for which the antenna is being deployed. Such a customized rectangular micro strip patch antenna is design for linear polarization and is simulated using IE3D. Key parameters included in simulation are VSWR, Return loss, S-Parameters, Z-parameters and smith chart. The planned antenna is capable of generating resonant frequency with single feeds. Experimental result for the characteristics of small strip antenna are conferred and mentioned in this paper.
\end{abstract}

\section{Keywords}

Micro strip Patch antenna, linear Polarization,

\section{INTRODUCTION}

Micro strip patch antennas (MPAs) are getting increasingly popular on wireless communication applications due to several specific features, which are not available with other antenna types. These antennas have a low profile and are conformable and easily integral with other electronic components. However, major inherent disadvantages of MPAs area unit slim information measure and low radial asymmetry. Therefore, style of little high-directivity, broadband/multiband MPAs has become a motivating downside for the antenna analysis community.

Among different performance improvement techniques, genetic algorithm (GA) has revealed towards useful in wide area of electromagnetism [1-3]. Genetic algorithm has been used to create MPAs with broad-band [4], multi-band [5], high-directivity [6], and miniature [7] and broadside radiation [8] characteristics. Optimize the patch shape and the feeding position to obtain required characteristics.

Micro strip antennas are engaging attributable to their lightweight, conformability and low value. These antennas are often integrated with written strip-line feed networks and active devices. This is often a comparatively new space of antenna engineering. The radiation properties of small strip structures are notable since the middle 1950's. The appliance of this kind of antennas started in early 1970's once conformal antennas were needed for missiles. Rectangular and circular small strip resonant patches are used extensively in a very kind of array configurations. A significant conducive issue for recent advances of small strip antennas is that the current revolution in electronic circuit shrinking led to by developments in massive scale integration. As standard Antennas are usually large and dear a part of an electronic system, small strip Antennas supported photolithographic technology are seen as an engineering breakthrough.
In its most elementary type, a small strip Patch antenna consists of a diverging patch on one aspect of an insulator substrate that contains a ground plane on the opposite aspect as shown in Figure1. The patch is usually made from conducting material like copper or gold and might take any attainable form. The diverging patch and also the feed lines square measure typically icon inscribed on the insulator substrate. [11]

\section{METHODOLOGY}

Run MGRID. Select File->New command. MGRID shows you the Basic Parameters dialog. In the Length group, select the Unit as "mil". In the Meshing Parameters group, change the Highest Frequency (Fmax) to $4.5 \mathrm{GHz}$ and the Cells per Wavelength (Ncell) to 15. Double click the "No.1 Grid Size..." in Layout and Grids group. Change it to 100 mils and select OK when you are prompted to edit the Grid Size. Select the Insert (or New) button in the Substrate Layers group. MGRID will prompt you for "Insert New Substrate". Enter "Top Surface, Ztop" as 31(mils). Enter the Dielectric Constant, Epsr $=5.9$. Select $\mathrm{OK}$ and the entered substrate is listed in the Substrate Layers list box. We do not need to change the Metallic Strip Types because metallic loss is normally not critical to antennas when the frequency is not very high. Select OK to continue. MGRID is ready for geometry input.

We are going to build a rectangle without the inset first. Select Entity->Rectangle. MGRID will prompt you for the parameters of the rectangle you want to build. Enter $(X, Y, Z)$ $=(0,0,31)$. Enter Length $=1512$ and Width $=1500$ in the Rectangle Properties group. Select $\mathrm{OK}$ to continue. A rectangle is created with centre at $(\mathrm{X}, \mathrm{Y}, \mathrm{Z})=(0,0,31)$

Press down "Shift", window the vertices 1 and 2 in Figure 5.2a to select them. Select Adv Edit->Cut into Polygon on Edge command. MGRID prompts you for the parameters. Please enter Cut Width $=115$ and the Cut Depth $=452$. Select OK. MGRID will build the inset as shown in Figure 2.b.

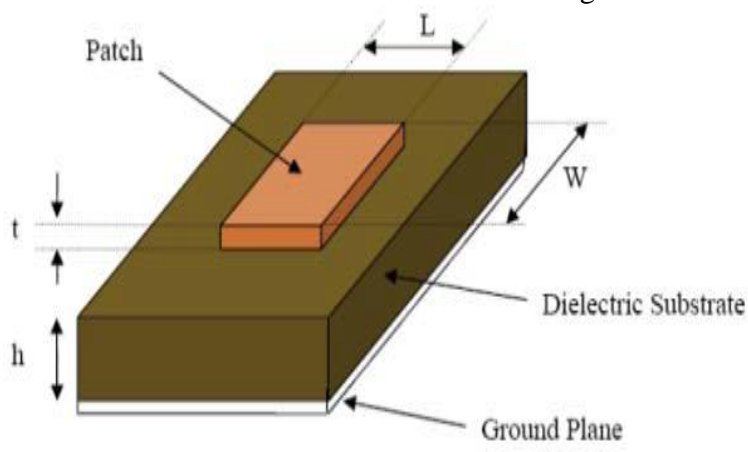

Figure 1: Architecture of Micro strip Patch Antenna 
Press down "Shift", window the vertices 3 and 4 in Figure 2.b to select them. Select Adv Edit->Continue Straight Path. Enter the Path Length $=1202(=452+750)$, Path Start Width $=$ Path End Width $=60$. Select OK. MGRID will build the feed line as shown in figure $2 . c$

Select Port->Port for Edge Group. Choose Advanced Extension for the De-Embedding Scheme. Check the Auto Adjustment. Select OK to accept other default settings. Window the edge formed by vertices 5 and 6 in Figure 2.c to define the port. Select Port>Exit Port to exit the state. Save the structure as: .lie3dlpracticelrpatch1.geo. The structure is ready to be simulated.

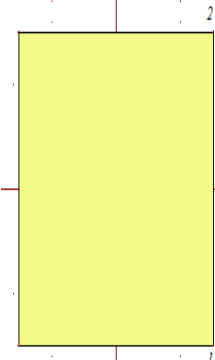

Figure 2.a

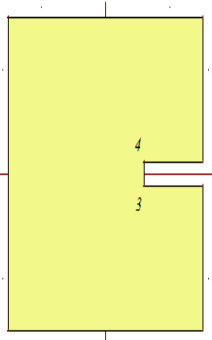

Figure 2.b

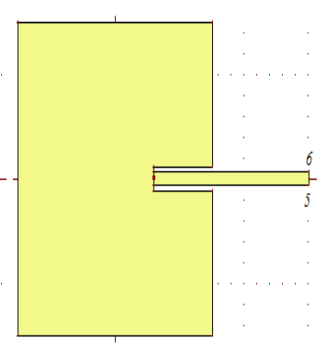

Figure 2.c
Select Process->Display Meshing. Select AEC Layers $=1$. The default AEC Ratio $=0.1$ and the corresponding Width $=$ 23.9433 mils. We know the feed line is 60 mils also the space in linking feed line \& edge of area is about 27.5 mils because it is $0.5 *(115-60)$ mils. We may want to reduce the AEC Ratio to 0.05 so that the AEC Width becomes smaller compared to the gap width. After Meshing the geometry is show in figure. 3

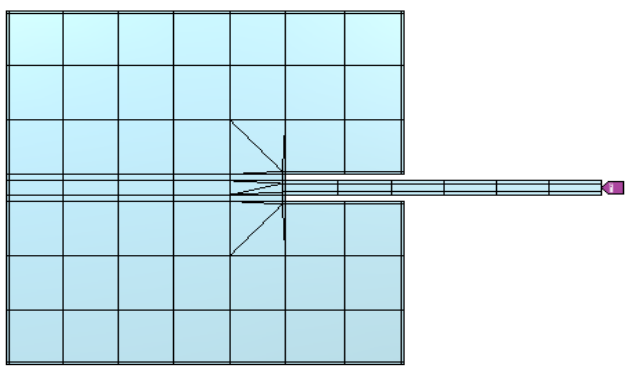

Figure: 3

Select Process->Simulate command. The Simulation Setup dialog comes up. We would like to simulate the structure from 3.5 to $4.5 \mathrm{GHz}$ with 151 frequency points. Select the Enter button in Frequency Parameters dialog. MGRID prompts you for the frequency range. Enter Start Freq $=3.5$, End Freq $=$ 4.5 , and Number of Freq $=100$. Select OK to add the frequency parameters into the list box. The AEC setting should be the same as before. Select and add the graphs and start simulation. After simulation result will be displayed for the graphs which are added.

\section{DESIGN PARAMETERS}

\begin{tabular}{|c|c|}
\hline Dielectric Constant & 5.9 \\
\hline Frequency Range & $3.5-4.5 \mathrm{GHz}$ \\
\hline No. of Frequency Sample & 100 \\
\hline Meshing Frequency & $4.5 \mathrm{GHz}$ \\
\hline
\end{tabular}

\section{SIMULATION RESULT}

The antenna behavior is optimized using IE3D software. Following results were obtained on simulation of the Antenna using above mentioned design parameters.

\section{VSWR (dB) Display}

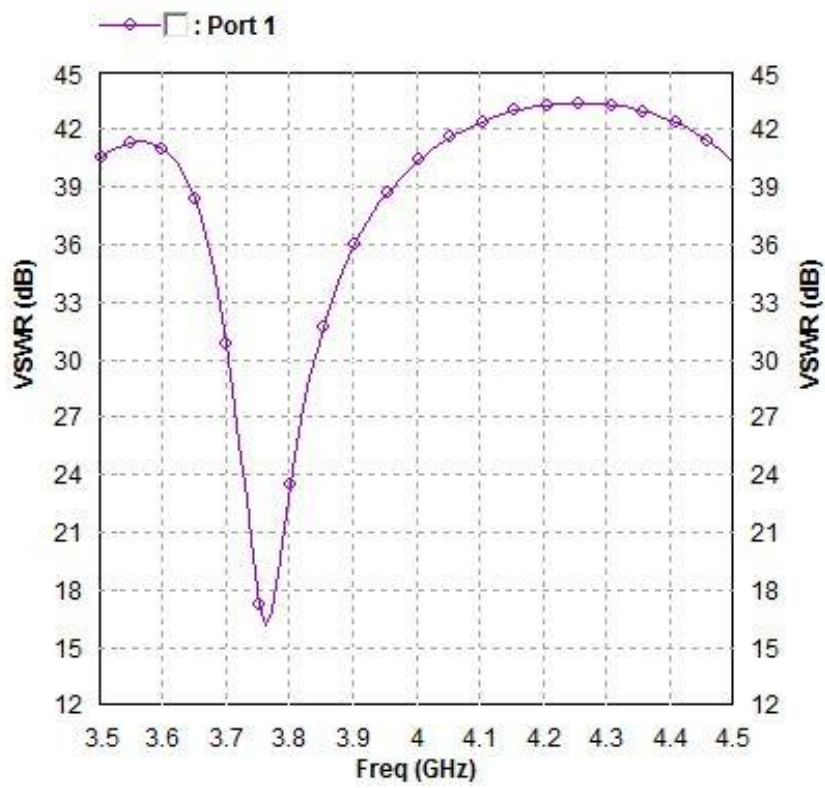

Figure 4: Frequency band has been narrowed down with Resonant frequency $=3.76 \mathrm{GHz}$

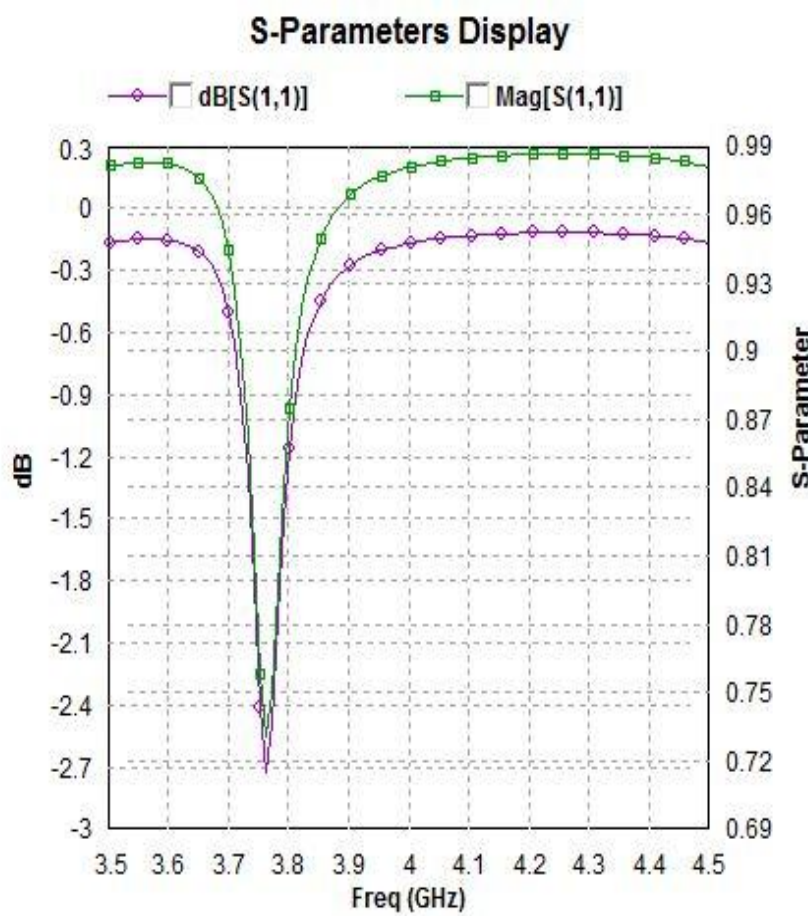

Figure 5: Curve of Return loss vs. Frequency. It measures tuned antenna return loss, Return Loss $=-2.7 \mathrm{~dB}$ at frequency $=3.77 \mathrm{GHz}$ 


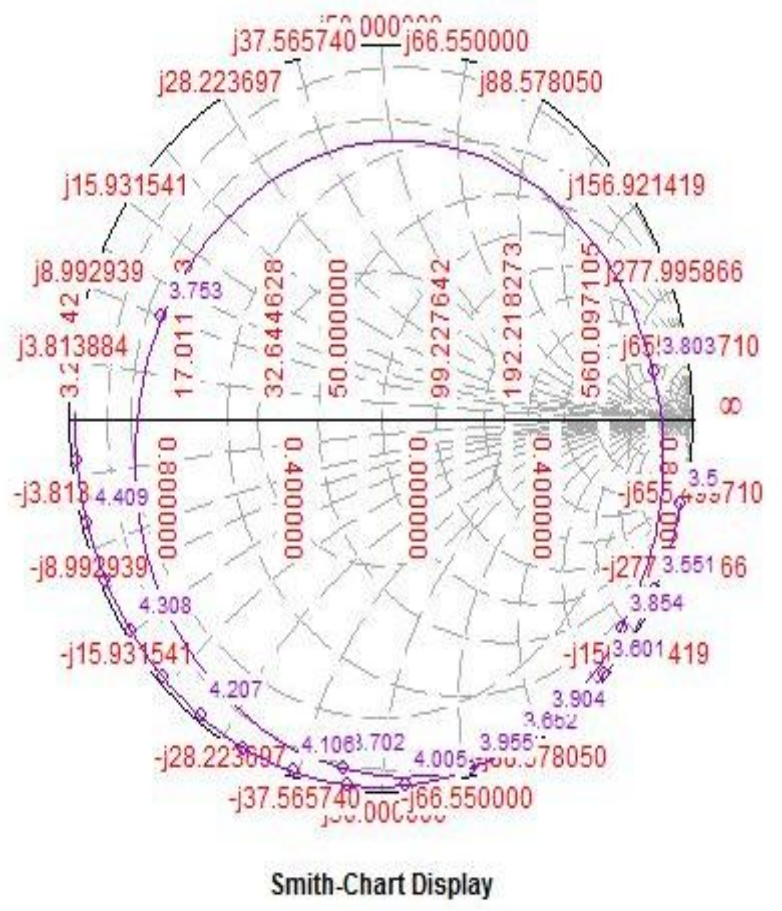

Figure 6: Smith Chart

\section{Z-Parameters Display}

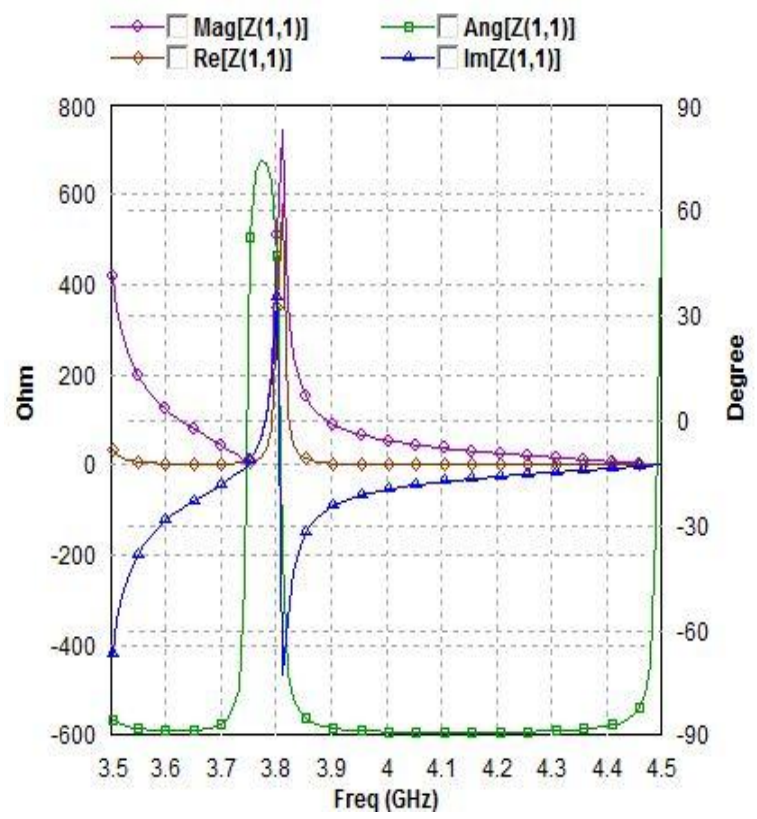

Figure 7: Curve of Impedance vs. Frequency for MPA having Impedance $=750 \mathrm{Ohms}$ at frequency $=3.82 \mathrm{GHz}$

\section{CONCLUSION}

So, we have successfully designed Linear Polarized Micro Strip Patch Antenna using IE3D software. We observed that for the frequency range of $3.5-4.5 \mathrm{GHz}$, the resonant frequency was $3.76 \mathrm{GHz}$ with dielectric constant=5.9. Thus we narrowed down the frequency band which will make the MPA suitable for linear polarization.

\section{REFERENCES}

[1] Haupt, R.L., "An introduction to genetic algorithms for electromagnetics", IEEE Antennas and Propagation Magazine, Vol. 37, No. 2, 7-15,1995.

[2] Johnson, .1.M., and Y. Rahmat-Samii, "Genetic Algorithms in Engineering Electromagnetics", IEEE Transactions on Antennas and Propagation, Vol.39, 721,1997 .

[3] Villegas, F.J., T. Cwik, Y. Rahmat-Samii and M. Manteghi, "A parallel Electromagnetic geneticAlgorithm optimization application for patch antenna design" IEEE Transactions on Antennas and Propagation, Vol. 52,2424-2435,2004.

[4] 1.M.1.W. Jayasinghe, D.N. Uduwawala, "Optimization of the performance of patch antennas using genetic algorithms", Journal of National Science Foundation, Vol. 41, No. 2, 115-122,2013.

[5] 1.W. Jayasinghe, 1. Anguera, and D.N. Uduwawala, "A simple design of multi band microstrip patch antennas robust to fabrication tolerances for GSM, UMTS, LTE, and Bluetooth applications by using genetic algorithm optimization," Progress In Electromagnetics Research M, Vol. 27,255-269,2012

[6] J.M.J.W. Jayasinghe, J. Anguera, and D.N. Uduwawala, "Genetic algorithm optimization of a high-directivity microstrip patch antenna having a rectangular profile", Radioengineering, Vo1.22, No. 3, 700-707, 2013.

[7] 1.M.1.W. Jayasinghe, D.N. Uduwawala, "A Novel Miniature Multi-Frequency Broadband Patch Antenna for WLAN Applications", 8th IEEE International Conference on Industrial and Information Systems, ICnS 2013, 361-363, Dec., Sri Lanka.

[8] J.M . .1.W. Jayasinghe, D.N. Uduwawala, and .I. Anguera, "Design of a genetic microstrip patch antenna with broadside radiation for GSM applications", International Journal of Scientific World, Vol. 2, No. 2, 84-87,2014.

[9] Sanjeev dwivedi, Abhishek Rawat, R.N.Yadav DESIGN OF U-SHAPE MICROSTRIP PATCH ANTENNA FOR WIMAX APPLICATIONS AT 2.5GHz, 978-1-46735999-3/13/2013 IEEE.

[10] M. T. Ali, S.Muhamud @ Kayat, N.R.Abd Rahman, and Norsuzila Ya'acob A Microstrip Patch Antenna with Aperture Coupler Technique at $5.8 \mathrm{GHz} 2011$ IEEE International Conference on System Engineering and Technology (ICSET)

[11] Z. 1. Dafalla, W. T. Y. Kuan, A. M. Abdel Rahman, and S. C. Shudakar Design of a Rectangular Microstrip Patch Antenna at $1 \mathrm{GHz} 2004 \mathrm{RF}$ AND MICROWAVE CONFERENCE, OCTOBER 5 - 6, SUBANG, SELANGOR, MALAYSIA. 